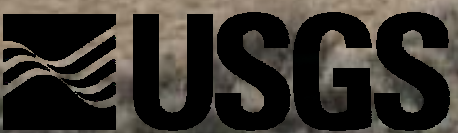

science for a changing world

In Cooperation with the Bureau of Land Management

\title{
Annual Report for 2004 Wild Horse Research and Field Activities
}

By Jason Ransom, Francis J. Singer, and Linda Zeigenfuss
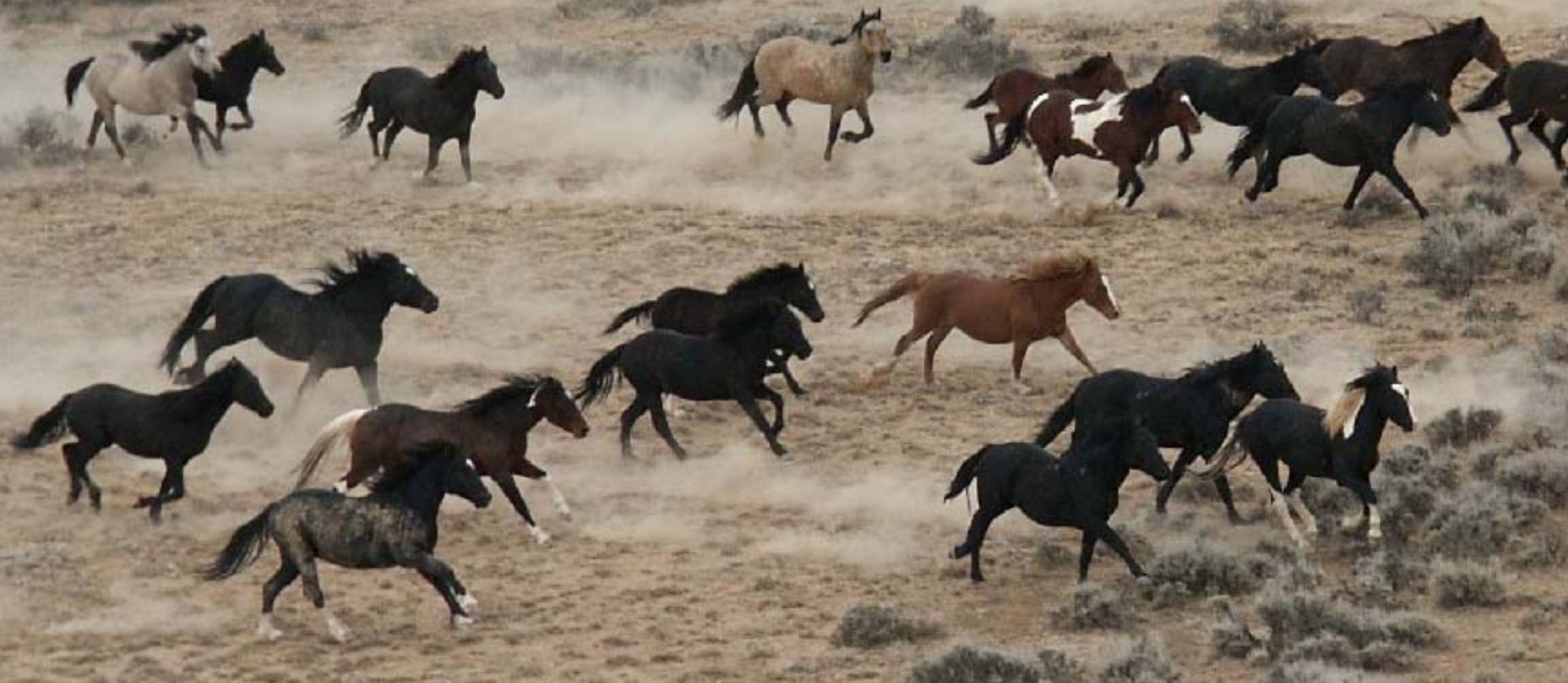

Any use of trade, firm, or product names is for descriptive purposes only and does not imply endorsement by the U.S. Government vitalite

\section{Open-File Report 2005-2005-1316}

U.S. Department of the Interior U.S. Geological Survey 


\section{U.S. Department of the Interior \\ GALE A. NORTON, Secretary \\ U.S. Geological Survey \\ Charles G. Groat, Director}

U.S. Geological Survey, Reston, Virginia 2005

Revised and reprinted: 2005

For more information about the USGS and its products:

Telephone: 1-888-ASK-USGS

World Wide Web: http://www.usgs.gov/

\section{Suggested citation:}

Ransom, J., Singer, F.J., and Zeigenfuss, L., 2005, Annual report for 2004 wild horse research and field activities: U.S. Geological Survey, Biological Resources Discipline, Open File Report 2005-1316, 19 p. 


\section{Contents}

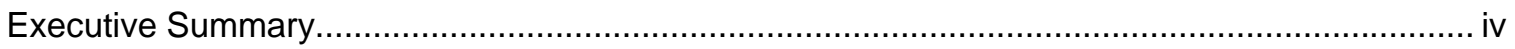

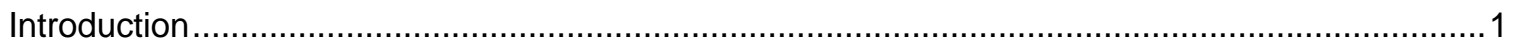

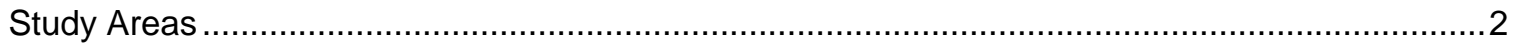

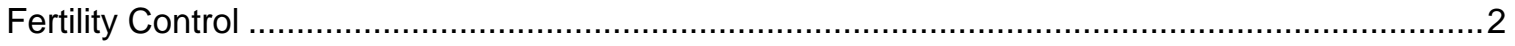

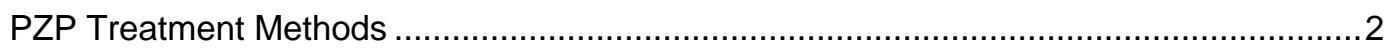

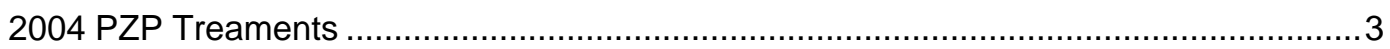

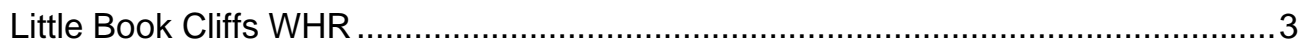

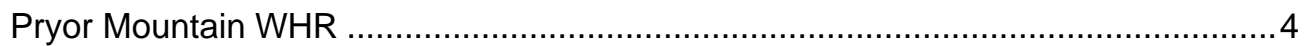

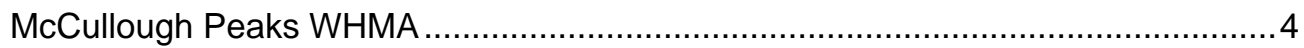

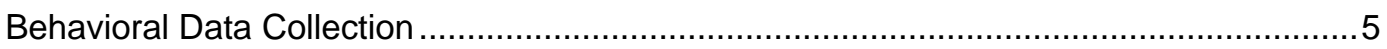

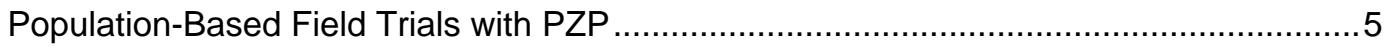

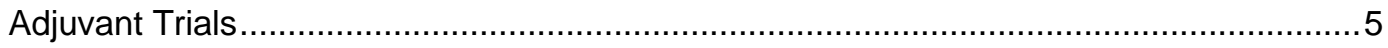

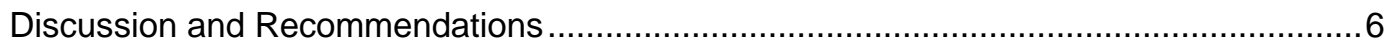

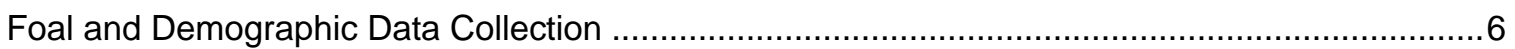

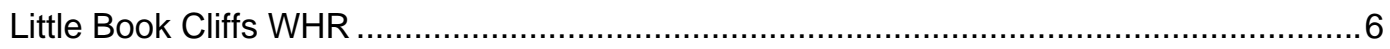

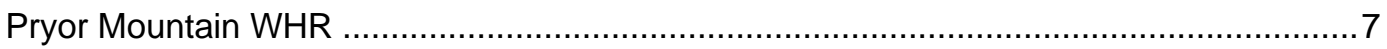

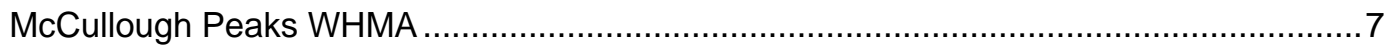

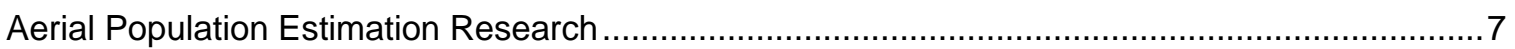

Mark-Resight with Sightability Correction Model.................................................. 8

Simultaneous Double-Count with Sightability Correction Model ..............................8

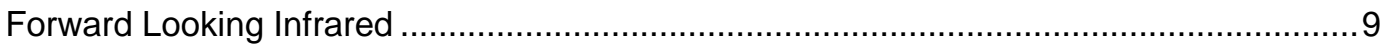

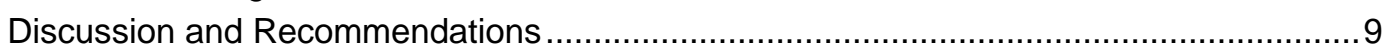

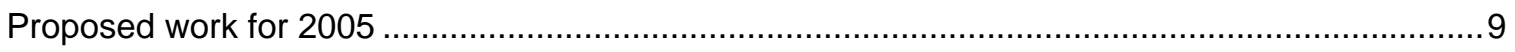

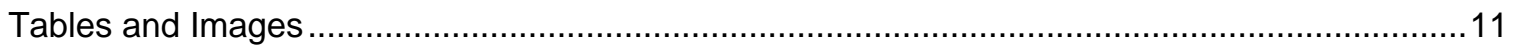

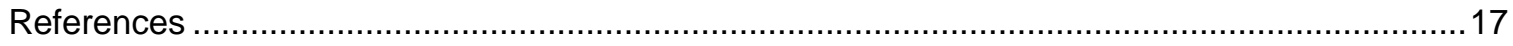

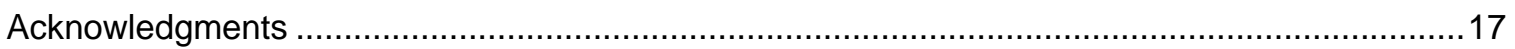




\section{Executive Summary}

The Bureau of Land Management (BLM) and U.S. Geological Survey-Biological Resources Discipline (USGS/BRD) continued wild horse research in 2004, investigating the strategic research elements of fertility control and population estimation. Fertility control research was focused on the individual-based porcine zonae pellucida (PZP) field trials at the Pryor Mountain Wild Horse Range (WHR), Little Book Cliffs WHR, and McCullough Peaks Wild Horse Management Area (WHMA). Aerial population estimation research was conducted on a number of western wild horse herds to test different survey techniques as applied to various habitat types and population sizes.

\section{Fertility Control}

PZP application to mares in the Little Book Cliffs and Pryor Mountain was in the form of remotely delivered 1-year liquid PZP and were primarily boosters to mares that had received PZP in the previous year(s). Mares in the McCullough Peaks received the 22-month time-released pellet form of PZP and were first treated in 2004. By the end of 2004, 38 horses on the Pryor Mountain WHR had received PZP injections, as had 29 horses in the Little Book Cliffs WHR, and 36 in the McCullough Peaks WHMA.

- Little Book Cliffs:

o The 2004 field season marked the first year in which the effects of immunocontraception could be observed in this herd. On a herd-wide scale, the foal rate dropped from $66 \%$ in 2003 to $35 \%$ in 2004 (a change of 31\%).

o No animals were observed exhibiting signs of behavioral depression, muscle tremors, or stiffness as a result of darting. Thirteen of 24 mares inoculated (54\%) appeared to exhibit some sign of dart trauma at the site of injection (swelling, nodule, persistent nodule, and/or abscess).

o Behavioral data collection consisted of 456 observations (approx. 13,680 minutes) from April 7 to October 19, 2004, on focal bands containing both treated and untreated mares.

o An October gather reduced the herd from 185 to 120 horses. No focal research animals were removed from the range.

- Pryor Mountain:

o Twelve mares were expected to be infertile in 2003 (19\% of mares 2 yrs and older in the herd) and none of them produced foals in 2004. On a herd-wide scale, the foal rate dropped from $48 \%$ in 2003 to $45 \%$ in 2004 (a change of 3\%).

o Predation events caused extensive foal loss in 2004, with a surviving foal rate of only $6.5 \%$. This change in herd dynamics caused a restructuring of fertility control strategy and only 8 mares were boostered in 2004. Five additional mares were primed, but not boostered.

o Three animals were observed exhibiting signs of stiffness after being darted. Five of 13 mares inoculated (38\%) appeared to exhibit some sign of dart trauma at the site of injection (swelling, nodule, persistent nodule, and/or abscess).

o Behavioral data collection consisted of 306 observations (approx. 9,180 min) from June 7 to October 27, 2004, on focal bands containing both treated and untreated mares. 
- McCullough Peaks:

o Immunocontraception was applied in October, and thus had no effect on the 2004 foaling rate $(69 \%)$. The first effects on herd growth rate should be seen in 2007, and the expected rate of efficacy is approximately $90 \%$ in that year.

o PZP was applied by syringe/jabstick, and post-treatment observations noted only 2 mares exhibiting small swellings at the injection site. No other mares exhibited any signs of swelling, nodules, stiffness, behavioral depression, muscle tremors, or abscesses.

o Behavioral data collection consisted of 217 observations (approx. 6,510 min) from June 5 to October 28, 2004, on focal bands containing only untreated mares.

o An October gather reduced the herd from 493 to 112 horses. The gather did not remove any mares or stallions that were members of the focal research bands.

\section{Aerial Population Estimation}

An aerial survey research team and work plan was developed in the summer of 2003, with input from various federal and state wildlife survey experts, and implementation of aerial survey tests began in October, 2003. The work plan outlined 5 techniques to test on wild horse populations: simultaneous double-count, sightability bias, mark-resight, distance sampling, and a combination method. A test of Forward-Looking Infrared was added to the plan in 2004.

- Mark-Resight with Sightability covariates:

o The initial test at McCullough Peaks produced an estimate of 356 horses (95 \% CI=349384). The known truth in the area surveyed was a population of 373 horses (+/- 2).

o A second test at the Little Book Cliffs was much more difficult due to extensive vegetation cover. The analysis is pending until the vegetation cover covariate data can be incorporated.

- Simultaneous Double-Count with Sightability covariates:

o This technique was used at six Wild Horse Management Areas in Wyoming, in 2004. These flights were scheduled BLM inventory flights that USGS assisted with by providing input on survey design, data analysis, and an extra observer. The flights contributed considerable data about the technique in question, but are not true tests of accuracy since the true population sizes are unknown.

- A test was conducted at Little Owyhee HMA, NV, using pre and post-gather surveys to establish truth. The pre-gather survey estimate was 706 horses, and the post-gather survey estimate was 214 horses. The estimated count difference between surveys is 492 horses. The known removal conducted between the surveys was 467 horses.

- Forward-Looking Infrared (FLIR):

o A two hour test flight of FLIR was conducted in a rural area around Boise, ID. Parameters tested included altitude, camera angle, image quality, and sweeping pattern. A full survey test FLIR in an HMA is scheduled in early 2005. 


\title{
Annual Report for 2004 Wild Horse Research and Field Activities
}

\author{
By Jason Ransom, Francis J. Singer, and Linda Zeigenfuss, U.S. Geological Survey \\ In Collaboration with Linda Coates-Markle, Bureau of Land Management
}

\section{Introduction}

As stated in the Wild Horse Fertility Control Field Trial Plan, the Bureau of Land Management (BLM) has an immediate need for a safe, effective contraceptive agent to assist in the management of the large number of wild horses on western rangelands. The BLM and the U.S. Geological Survey/Biological Resources Discipline (USGS/BRD) are testing the immunocontraceptive agent porcine zonae pellucida (PZP) in field trials with three free-roaming herds of western wild horses. Extensive research has already been conducted on the safety, efficacy, and duration of PZP applications in both domestic horses and feral horses on eastern barrier islands, and in some select trials with wild horses in Nevada, managed by the BLM. However, significant questions remain concerning the effects of PZP application on behavior, social structure, and harem dynamics of free-ranging animals. These questions are best answered with field trials on wild horse herds under research protocols. The ultimate goal is to provide the BLM with the protocols and information necessary to begin using fertility control to regulate population growth rates in wild horse herds on a broader scale. Fertility control is intended to assist the conventional capture, removal, and adoption process as a means of controlling excess numbers of wild horses and burros, and to greatly reduce the adoption costs and numbers of animals handled. Fertility control is not intended to totally replace the removal and adoption process.

The USGS/BRD began assisting the BLM with field trials of immunocontraceptive fertility control of wild horses in early 2001. PZP treatments have taken place at 2 field trial sites, Pryor Mountain Wild Horse Range (WHR) and Little Book Cliffs WHR, each year through 2004. The treatments consisted of an initial primer injection followed by a booster injection each year. The booster injection is required in order to raise (and maintain) the titer levels of mares high enough for effective contraception (Liu and others, 1989). Treatments at a third field trial site, McCullough Peaks Wild Horse Management Area (WHMA), began in 2004 using a time-released form of PZP. By the end of 2004, 38 horses on the Pryor Mountain WHR had received PZP injections, as had 29 horses in the Little Book Cliffs WHR, and 36 in the McCullough Peaks WHMA. In 2004, USGS/BRD and BLM continued intensive research efforts at all three field locations, which included; treatment of wild horse mares with PZP in all 3 herds, behavioral research to investigate potential affects of PZP treatment, continued tracking of demography and foal production in all three herds, and investigation into aerial population estimation techniques. Detailed descriptions of the planning and objectives of these research topics can be found in the Wild Horse and Burro Management Strategic Research Plan (USDOI, 2005) and the Wild Horse Fertility Control Field Trial Plan (Singer \& CoatesMarkle, 2002). Field work in 2004 was conducted by USGS/BRD and BLM staff with the assistance of many dedicated individuals. See Acknowledgments for more details.

This report is meant to highlight the activities of the 2004 field season, as well as to provide a general overview of the data collected. More in-depth data analysis will be conducted following the conclusion of each phase of the research, which in many cases will not be possible until data have been collected for several seasons. 


\section{Study Areas}

The Pryor Mountain WHR is located adjacent to Bighorn Canyon National Recreation Area near Lovell, Wyoming. It is 39,650 acres of mixed terrain that consists of desert, forested mountain slopes, and high alpine meadows. The herd currently totals roughly 140 wild horses, many of which congregate during the summer months in the subalpine meadows. This congregation facilitates a large amount of social interaction and stallion competition, and is the focus of many of the behavioral observations conducted in this research project.

The Little Book Cliffs WHR is located in western Colorado, about 8 miles northeast of Grand Junction. It is 36,113 acres of very rugged terrain (deep canyons and badland formations) that in areas is densely vegetated with piñon, oak, and sage. The herd of approximately 185 wild horses was gathered and reduced to appropriate management level (AML) of 120 this season (USDOI, 2004b). Some horses travel seasonally between the lower canyons and the higher elevations, but other horses are not migratory. The nature of the terrain and vegetation often makes it difficult to see the horses on this range. Like the McCullough Peaks, water can be scarce and may be a source of prompting interactions between bands. The harems on this range do not routinely interact with other harems on a prolonged basis.

The McCullough Peaks WHMA is located 20 miles east of Cody, Wyoming. It is 110,000 acres of predominantly open sagebrush prairie, with some badlands along the western edge of the range. The herd of approximately 490 wild horses was gathered and reduced to the AML of approximately 110 animals in October 2004 (USDOI, 2004a). There is no single seasonal congregation area for horses on this range, and some areas are partitioned by fenced cattle allotments. Water can be very scarce and could be a large factor in determining horse movements, and thus, interactions between harems.

\section{Fertility Control}

\section{PZP Treatment Methods}

Initial PZP treatments were delivered by hand injection during the gathers of 2001 and 2002; all subsequent treatments on the Little Book Cliffs WHR and Pryor Mountain WHR have been delivered remotely. In 2004, we continued to use scoped Pneu-dart 193 rifles and Dan-Inject CO2 blowguns, with $1 \mathrm{cc}$ Pneu-dart darts (1 1 1 2 " needles). Primary treatments (primers) were composed of $0.5 \mathrm{cc}$ PZP and $0.5 \mathrm{cc}$ Freund's Complete Adjuvant (FCA), and all secondary injections (boosters) were composed of $0.5 \mathrm{cc}$ PZP and $0.5 \mathrm{cc}$ Freund's Incomplete Adjuvant (FIA). On October 6, 2004, thirty-six mares at McCullough Peaks HMA were administered immunocontraceptive treatments. These mares were treated in the chute via hand or jabstick injection, and each received an initial dose of $0.5 \mathrm{ml}(100 \mu \mathrm{g})$ of PZP combined with $0.5 \mathrm{ml}(100 \mu \mathrm{g})$ of FCA. An additional injection was given consisting of three time-release pellets (a one month, three month, and twelve month pellet) containing PZP and adjuvant QA-21. These pellets were produced through a cold evaporation process ${ }^{1}$ and pre-loaded into 14 gauge needles by the Medical College of Ohio. The combined targeted infertility period of these injections is 22 months. All injections were placed in the hind quarter, and delivered by trained USGS, BLM, Zoo Montana, or Medical College of Ohio personnel.

Remote delivery of PZP was conducted on a total of 37 mares with the PZP one-year agent in 2004. These treatments were delivered by both rifle and $\mathrm{CO} 2$ blowgun in the Little Book Cliffs and Pryor Mountains, but the nature of the horses and habitat types mandated that most deliveries were by rifle in the Little Book Cliffs and by

\footnotetext{
${ }^{1}$ These are very small pellets created by a modification of the heat/extrusion pelleting process that uses heat to melt the polymer/PZP/adjuvant mixture and extrude it into strands that are cut into pellets of required mass. This modified method uses an organic solvent (non-degrading to the ingredients) instead of heat to liquefy the polymer mixture. As the solvent evaporates, the material becomes viscous enough to be formed into pellets. The absence of heat assures good integrity of the ingredients, and this process also has much less loss of ingredients associated with it than does the heat/extrusion process. (J. Turner, personal communication, January 20, 2005).
} 
blowgun in the Pryors. The high number of dart failures last season was mitigated in 2004 by a cooperative effort between the Science and Conservation Center of Zoo Montana and Pneudart, Inc. to correct the manufacturing problem. In 2003, 29\% of the darts failed upon delivery; whereas, in 2004, $0 \%$ failed upon delivery.

Treated mares were monitored for any potential swelling, stiffness, muscle tremors, nodules, granulomas, abscesses, and/or behavioral depression, which might develop subsequent to injections. We defined a 'nodule' as a lump that appeared less than 2 weeks after an injection. A lump that appeared or persisted longer than 2 weeks after an injection was defined as a persistent nodule. Physical evidence of a persistent nodule actually being a granuloma formation would require histopathological examination of the nodule. This has not been possible to date, but an examination will be made of any nodules should a treated animal die of natural causes.

\section{PZP Treatments}

\section{Little Book Cliffs WHR}

The 2004 field season marked the first year in which the effects of immunocontraception could be observed in this herd. The foal rate, calculated with all females 2 yrs and older, dropped from $66 \%$ in 2003 to $35 \%$ (a change of $31 \%$ ). Of the 24 mares currently treated (36.9\% of mares 2 yrs and older in the herd), 4 produced foals in 2004. One of the mares that foaled had received questionable booster injections (broken darts). Two had received booster injections long past the target date and likely had a window of fertility. The fourth mare received her boosters on time with functioning darts and may simply be less receptive to the antigen/antibody response. Eliminating the 3 mares from analysis whose vaccinations were subject to human error, and thus considered treatment failures, 1 of 21 treated mares (or $4.7 \%$ ) foaled.

Twenty-four of the 29 mares previously treated in the Little Book Cliffs were successfully boostered in 2004. Two mares were dropped from treatment after their primer dose in 2002 because they were too elusive to dart. An additional 2 mares were dropped in 2003 due to natural mortality, and one mare was dropped from treatment due to management decisions. Although all 24 mares were boostered this season, 4 were darted after their theoretical due date. Three were darted within about a week and a half of their due date; however, one horse was not located and darted until 46 days past her due date. These cases were due to difficulties in locating or approaching them during the time period in which they needed to be boostered. Since there is some variance in the duration of infertility based upon individual immune responses to the vaccine (Fraser, 1980), it is not known if the boosters were in time to retain infertility or if there was a window of fertility during which the mares may have conceived. Fecal samples from 11 treated mares were collected during the October 2004 gather in order to test for pregnancy. Ten of these mares tested non-pregnant and 1 was inconclusive. Two of the mares that received late boosters (46 days and 12 days) tested non-pregnant. The heavily vegetated terrain and flighty nature of the horses continues to make this area challenging for remote darting; however, with good seasonal timing and persistence, remote delivery of the vaccine was manageable.

A total of 55 follow-up observations were made of all 24 treated horses currently on the range. The October gather provided good opportunity to view many of the treated mares up close. No animals were observed exhibiting signs of behavioral depression, muscle tremors, or stiffness as a result of darting. Thirteen of 24 mares inoculated (54\%) appeared to exhibit some sign of dart trauma at the site of injection (swelling, nodule, persistent nodule, and/or abscess). Two mares exhibited small swellings on the same day they were darted, but subsequent observations detected no signs of trauma. One additional mare also showed signs of a 1-inch swelling, but was not observed again in 2004 (Image 1). The fourth mare to show signs of swelling was observed again at 3 weeks and the swelling had manifested into a persistent nodule. Several mares exhibited persistent nodules ranging from $1 / 2$ to 1 inch in diameter. Three of these horses had persistent nodules 7 weeks post-inoculation and were not observed again in 2004. In addition, one mare had a persistent nodule seen at 5 weeks post-inoculation, but it was not observed at 8 weeks. This particular mare (\#9305) had exhibited persistent nodules from darts in previous years, which were not observed in 2004. Another mare (\#9604) that had shown a persistent nodule from a 2003 inoculation continued to exhibit it in 2004 (54 weeks post-inoculation) (Image 2). At 9 weeks post-inoculation, this mare showed an additional persistent nodule from her 2004 booster. One mare developed a nodule and abscess 9 days post- 
inoculation, which later turned into a persistent nodule (Image 3). It was last observed 7 weeks post-inoculation at $1 / 2$ inch diameter. This mare also still exhibits a persistent nodule from a previous booster 75 weeks post-inoculation, though it has diminished in size. One mare exhibited a small nodule 3 weeks post-inoculation, but was not observed again in 2004. Mare \#9307 was observed to have a possible nodule 2 weeks post-inoculation, but the mare could not be approached closely enough to confirm the condition and was not seen again in 2004. Lastly, mare \#9723 was observed 3 weeks post-inoculation with a small abscess. This mare also abscessed at the two prior inoculation sites in 2003.

\section{Pryor Mountain WHR}

Treatments in this herd have followed a different strategy than in the Little Book Cliffs herd due to management needs; thus, only young (1-2 yrs) and old (14+ yrs) mares have been treated. Of the 12 mares expected to be infertile in 2004 (19\% of mares 2 yrs and older in the herd), none produced foals. On a herd-wide scale, the foal rate dropped from $48 \%$ in 2003 to $45 \%$ in 2004 (a change of 3\%).

Darting operations at the Pryor Mountain WHR took place July-September, 2004, and were conducted by BLM and Zoo Montana staff. As in previous years, the majority of horses treated were easily found and approachable, thus darting operations were generally quick and efficient to perform. Five yearlings were primed in July 2004 and not boostered due to increasing predation events on the herd. The only mares that received boosters this season were the 6 older mares (14 yrs and older) that had begun treatment in 2003, plus 1 other older mare that was primed and boostered this season, and one $2 \mathrm{yr}$ old filly that was in poor body condition. To date, 38 mares have been treated on this range, but only the aforementioned 8 are currently boostered.

Follow-up observations were much easier to conduct at the Pryor Mountain study site. Twelve of the 13 mares darted were observed at least once, with many being observed several times after each injection. A total of 31 observations were made of 13 individual horses, and most animals were observed within 24-48 hours after injection. No animals were observed exhibiting signs of behavioral depression or muscle tremors as a result of darting. Three mares showed temporary signs of stiffness, all of which disappeared within 14 days of the injection. Five horses exhibited some temporary swelling at the injection site, ranging in diameter from 3 to 6 inches. Three of these mares continued to exhibit swelling when they were last observed, 14 days post-inoculation. Six mares exhibited small nodules, three of which later developed into persistent nodules. One nodule had disappeared at 8 days postinoculation and another had disappeared 10 days post-inoculation. The other four horses exhibiting nodules still retained those 14 days post-inoculation, which is the last time they were observed in 2004. These four nodules were from primer injections.

\section{McCullough Peaks WHMA}

Immunocontraception treatments in the McCullough Peaks were first administered in October, 2004, so there is no expected impact on foal rate for 2005 . The first data on efficacy will be available from fecal steroid pregnancy tests in the fall of 2005 and foaling rates during the 2006 season. This will be critical first data on the performance of the cold-evaporated pellet form of PZP. Only one initial PZP treatment did not deliver correctly, and the mare was re-treated. All other treatments were successfully delivered. All treated mares were freeze-marked on the left side of the neck with a standard-size iron, and numbered with 2 digits for their birth year and then sequentially as 839001 through 839036 (USDOI, 2004c). Blood was drawn for pregnancy testing as well as genetics. The Clinical Endocrinology Laboratory of University of California-Davis ran a full equine pregnancy panel (estrone sulfate and progesterone analysis) on each blood sample, and all 36 mares exhibited levels consistent with pregnancy.

Post-inoculation observations were conducted on all 36 mares one day after treatment. The animals were released from the holding corrals that day and not observed again in the 2004 season. Each mare was observed for one hour. Two mares exhibited small swellings at the injection site. No other mares exhibited any signs of swelling, nodules, stiffness, behavioral depression, muscle tremors, or abscesses. There were no post-treatment observational differences between injections delivered by hand injection versus jabstick. 


\section{Behavioral Data Collection}

In 2004, behavioral data collection and methodologies remained as outlined in the 2003 annual report (Ransom and others, 2004). Analysis of seasonal behavior data is deferred until all of the field trial data is collected and can be analyzed in its entirety.

\section{Little Book Cliffs WHR}

Field staff performed 456 observations (approx. 13,680 minutes) from April 7 to October 19, 2004, with data collected on a total of 1,975 observation horses. Each unique horse was observed an average of 46.89 times. The observations resulted in the following sample sizes; 7,458 spatial relationships, 402 stallion activity budgets, 973 untreated mare activity budgets, 708 treated mare activity budgets, and 497 all-occurrence behaviors. We continued to find behavioral observations challenging to conduct in the Little Book Cliffs WHR. Thick vegetation, highly reactive horses, and rugged terrain made it difficult to conduct prolonged observations and/or to observe the finer details of behavior. The addition of a full-time field technician greatly improved the total number of observations conducted in the 2004 season.

\section{Pryor Mountain WHR}

The Pryor Mountain WHR continued to provide an exceptional venue for behavioral observations in 2004. Field staff performed 306 observations (approx. 9,180 min) from June 7 to October 27, 2004, with data collected on a total of 1,283 observation horses. Each unique horse was observed an average of 38.13 times. The observations resulted in the following sample sizes; 4,564 spatial relationships, 306 stallion activity budgets, 388 untreated mare activity budgets, 241 treated mare activity budgets, and 536 all-occurrence behaviors.

\section{McCullough Peaks WHMA}

Behavioral observations for pre-treatment data were conducted at McCullough Peaks WHMA in 2004. Field staff performed 217 observations (approx. 6,510 min) from June 5 to October 28, 2004, with data collected on a total of 1,168 observation horses. Each unique horse was observed an average of 30.71 times. The observations resulted in the following sample sizes; 5,011 spatial relationships, 324 stallion activity budgets, and 835 untreated mare activity budgets. Observations of 224 all-occurrence behaviors were recorded. The same unique attributes to this herd were observed again in 2004; much larger band sizes (averaging twice the size of either of the other research herds) (Table 1) and some bands had multiple reproductively active males.

\section{Population-Based Field Trials with PZP}

The BLM and USGS have continued the series of experiments with the 22-month PZP time-release pellets. The purpose is to determine what effect on population growth rate the 22-month agent has when used within the normal 4-year gather cycle. These efforts are led by the BLM Wild Horse and Burro National Program Office, with substantial support from various field offices, especially in Nevada. The USGS will assist with monitoring design and data analysis, as requested. In fiscal year 2004, a total of 779 mares were treated with the 22-month timerelease form of PZP in 13 HMAs.

\section{Adjuvant Trials}

The BLM completed the Modified Freund's Adjuvant trial at Nevada's Palomino Valley Center in September, 2004. Blood sample analysis was conducted by the Science and Conservation Center of ZooMontana, and the results have not yet been published. 


\section{Discussion and Recommendations}

\section{PZP Treatments}

Remote darting operations went much smoother in 2004 than in 2003. This was primarily due to the darts functioning properly upon delivery. In the Little Book Cliffs WHR, we still found some difficulty in keeping the PZP frozen for long periods of time in the field. The use of dry ice and camp freezers provided for adequate cooling in most situations. The reactive nature of some of the horses also remained a challenge, as did the rugged habitat, which led to difficulty in locating some of the mares. Though all of the contracepted mares in the Little Book Cliffs did receive their boosters, some were delivered after the target date.

\section{Field Trial Herds}

Treatment protocol at the Pryor Mountain WHR continues to change, due to the large numbers of yearling and foal mortalities this year. It has become necessary for management to stop treatment of the younger mares as per their previous plans. This trend will likely continue in the foreseeable future and only the older mares will be treated with PZP. From a research perspective, the USGS/BRD team feels collection of behavior data can still be very useful in order to investigate post-treatment behaviors and obtain some control data on 1- and 2-yr age classes (which were previously under-represented as an untreated age class). The Pryor Mountain WHR also still remains an excellent herd for genetic and demographic research.

The more intensive focus placed on the Little Book Cliffs WHR in 2004 delivered a considerable increase in volume and quality of data this season. We intend to maintain the full-time technician position at this site in order to continue this productivity.

\section{Foal and Demographic Data Collection}

The USGS/BRD continued to compile annual demographic data for this research effort at all 3 study areas. This demographic data consists of herd composition (sex and age), foal production, mortalities, band sizes and composition, and individual horse identification and documentation. Collecting this information in such challenging environments and situations has only been accomplished due to the dedication and extreme efforts of many volunteers, along with BLM and USGS employees. Horses were systematically photographed, identified, and entered into the Wild Horse Identification Management System (WHIMS). Each band was observed and documented as to composition, sex, and age class. Actual ages are known for most of the research horses by veterinary assessment at gathers and detailed documentation of foal births. Foal production was noted from observed pregnancies and follow-up observations of new foals. Some pregnancy data also exists from fecal steroid analysis in the Pryor Mountain WHR and Little Book Cliffs WHR, and blood steroid analysis from McCullough Peaks WHMA. Blood samples from all 3 areas are also being analyzed for genetic composition by the University of Kentucky. Known mortalities reported are only the numbers of carcasses observed or reports that were confirmed. In the Pryor Mountain herd, identifiable individual horses that have not been seen for $>2$ years are then considered mortalities (no horse in this herd has disappeared for 2 years and then been observed again). Horses that have not been seen in the current year and may/may not be alive are recorded as missing/unaccounted for.

\section{Little Book Cliffs WHR}

Herd composition during the 2004 field season consisted of 31 known bands, each with a single dominant harem stallion. An additional 22 colts (yearlings and 2 yr olds) also ran in the herd. There were 21 adult male bachelors in the herd that did not run with a band. Sixty-five mares comprised the breeding population and they contributed 23 foals (11 colts, 7 fillies, 5 unknown gender) in 2004. Total foal rate (calculated for all mares 2 yrs 
and older) was $35.4 \%$, and surviving foal rate (alive as of Sept 30) was the same since no foal mortalities were recorded. Six horses were unaccounted for or missing (in addition to 13 missing from previous years). Three known adult mortalities were recorded ( 2 mares, 1 stud). The ratio of adult stallions to adult mares was 94:100. The total pre-gather herd size was estimated at 185 horses (+/- 19) (Table 2).

Post-gather herd composition resulted in an estimated total of 47 male horses and 68 female horses, with 9 of these animals being foals ( 3 female, 1 male, 5 unknown) for a total herd size of $120(+/-19)$ (Table 3$)$. The postgather ratio of adult stallions to adult mares is 90:100. There was one mortality recorded during the capture (a stallion was euthanized due to health conditions unrelated to the gather). It is interesting to note that 5 horses were captured that had not been seen in 4-5 years and were previously on the missing/deceased list.

We continued to record body condition for each PZP treated mare and each horse involved in behavioral observations in 2004. This was performed in the Little Book Cliffs, Pryor Mountain, and McCullough Peaks using a 0-5 body score system (Rudman and Keiper, 1991). Analysis will not be conducted until protocols can be developed to incorporate the many possible covariates involved, and to correct for repeated sampling on individual horses (a repeated measures analysis will be explored).

\section{Pryor Mountain WHR}

Herd composition in 2004 consisted of 33 bands, each with a single dominant harem stallion. There were an additional 30 bachelors that did not run with a band. Nine colts (yearlings and $2 \mathrm{yr}$ olds) also ran with the bands. Sixty-two mares comprised the breeding population and contributed 28 foals (13 colts, 13 fillies, 2 unknown gender). The total foal rate (calculated with all mares 2 yrs and older) was $45 \%$, and the surviving foal rate (alive as of Oct 31) was $6.5 \%$. Twelve horses were unaccounted for or missing, and 15 yearling mortalities and 24 foal mortalities were recorded. One adult mortality was recorded. The ratio of adult stallions to adult mares was 107:100. The total herd size is estimated at 142 horses (+/- 12) (Table 2). Mountain lion depredation is the suspected cause of the exceptionally high mortality rates among the foal and yearling age classes. None of the deceased animals had been treated with PZP.

\section{McCullough Peaks WHMA}

Herd composition during the 2004 field season consisted of 47 bands, each with a dominant harem stallion. An additional 20 male horses ran within the bands, and some exhibited reproductive behaviors even though they were not the band stallions. There were $48-65$ bachelors that did not run with a band. Sixty-six young males ( 1 and $2 \mathrm{yr}$ olds) also ran in the herd, as did 34-51 horses of unknown sex. There were 143 mares comprising the known breeding population and they contributed 98 foals ( 39 colts, 17 fillies, 42 unknown gender) in 2004. Two foal mortalities were recorded. Total foal rate (calculated with all mares 2 yrs and older) was $68.5 \%$. The surviving foal rate was $67.1 \%$. No adult mortalities were recorded. The ratio of known adult stallions to known adult mares was 89:100. The total pre-gather herd size was estimated at 510 horses; however, 17 horses were found to be discrepancies upon gather. This is likely due to some bachelors/unknown horses being double-counted in the field due to misidentification, unclear associations, and/or band interchanges. The actual pre-gather herd size was recalculated to be 493 horses (Table 2).

Post-gather herd composition resulted in an estimated total of 67 male horses and 45 female horses, with 7 of these animals being foals ( 5 female, 2 male). The post-gather ratio of adult stallions to adult mares was 117:100. There were 2 mortalities recorded during the capture ( 1 adult and 1 foal were euthanized due to health conditions unrelated to the gather). Total post-gather herd size was estimated at 112 horses (Table 3 ). 


\section{Aerial Population Estimation Research}

A stated goal of the BLM Wild Horse and Burro Program is to conduct a population survey of each wild horse or wild burro herd at least every 4 years. With a limited budget for flights, as well as increasing demand for reliable information on which to base management decisions, wild horse and burro managers need standardized, tested, defensible, cost effective, yet easy-to-use aerial population estimation techniques for wild horse and burro herds in a range of habitat types and across a range of population sizes and densities. The accuracy and precision of current wild horse survey methods has not been rigorously tested. Thus, a statistically valid estimation technique with confidence intervals is needed.

An Aerial Survey Research Team and work plan were developed in the summer of 2003, with input from various federal and state wildlife survey experts, and aerial survey tests began in October, 2003. The work plan outlined 5 techniques to test on wild horse populations: simultaneous double-count, sightability bias, mark-resight, distance sampling, and a combination method. A test of Forward-Looking Infrared was added to the plan in 2004.

\section{Mark-Resight with Sightability Correction Model}

The first test of the Mark-Resight technique was conducted October 21-23, 2003 on the McCullough Peaks WHMA. This was performed using a Bell 206BIII helicopter at low altitude with the doors removed. Two crew members took photographs (1 digital, 1 film) of each group of horses encountered. A third crew member recorded data, including 6 sightability covariates for each sighting (motion, sun direction, group size, topography, color contrast, vegetation cover). The survey was performed on transects spaced roughly 2 miles apart. Two days later, a second flight was flown using the same parameters, except that transects were staggered between those from the first flight. Each survey took 3.5 hours of flight time. Photographs were compared from each flight to assess which horses were seen on both flights vs. horses that were unique to one flight or the other. The initial analysis of data from this test suggested a slight undercount; however, during the Sep 29-Oct 7, 2004 gather, new information regarding the true population size was obtained (some horses had been listed twice in the ground inventory). The recalculated analysis suggests that we saw $82.6 \%$ of the total population on the first flight and $88.2 \%$ of the total population on the second flight. Collectively, we saw $92.8 \%$ of the total known population. The total estimate using this analysis is that the population at the time of the flight was 356 horses (95\% CI=349-384). The known population in the area surveyed was 373 horses (+/-2) (this number does not include horses known to be outside of the survey area at the time of the flights).

A second test of the Mark-Resight technique was conducted September 15-16, 2004 on the Little Book Cliffs WHR. This was performed using a B4763B1 Soloy helicopter with the passenger-side door removed. One crew member took digital photographs of each group of horses and 1 crewmember recorded data, including 5 sightability covariates for each sighting (motion, sun direction, topography, vegetation cover, group size). The extensive vegetation cover and rugged topography made it challenging to obtain good ID photos of each horse; however, the survey was successfully conducted and we had very little difficulty matching up the mark/resight images after the flights. The following day the survey was repeated, except that transects were flown perpendicular to the direction used on the first flight. Due to the vegetation and nature of the horses, the survey required the same amount of flight time as McCullough Peaks even though the actual area was roughly $1 / 3$ the size (Table 1). We saw $55.1 \%$ of the total population on the first flight and $50.8 \%$ of the total population on the second flight. Collectively, we saw $72.4 \%$ of the total known population. A final analysis of this survey data is currently underway.

\section{Simultaneous Double-Count w/Sightability Correction Model}

A test combining Simultaneous Double-Count with a Sightability Bias Correction Model was begun in the Little Owyhee and Snow Storm Mountains HMAs, NV, August 11-13, 2004. The analysis suggested that the combined observers saw 99.7\% of the horses in Little Owyhee and 99.9\% in the Snow Storms. The rear observer saw 3-5\% less groups than the front observers. The sightability model showed considerable weighting for group size 
and distance as affecting the horses' ability to be seen. The post-gather flight was conducted November 12-13, 2004. The sighting conditions were much more difficult during the second survey due to moisture, low clouds, and lack of dust trails; however, protocols and procedures for each survey were the same. Analysis of data from these flights is currently underway. Initial results show that the first survey produced a raw count of 701 horses, with a calculated estimate of 706 horses, and the second survey produced a raw count of 194 horses, with a calculated estimate of 214 horses. The estimated count difference between flights is 492 horses. The known removal conducted between the surveys was 467 horses. Data from these flights is being analyzed by count unit in order to provide more detailed results of this test.

USGS also assisted Wyoming BLM specialists with this technique Feb 22-25, 2004, at Dishpan Butte, Conant Creek, Rock Creek, and Muskrat Basin HMAs, and March 1-5, 2004, at Adobe Town and Salt Wells HMAs. These flights were scheduled BLM inventory flights that USGS assisted with by providing input on survey design and an extra observer. The flights contributed considerable data about the precision of the technique in question, but the accuracy cannot be tested against known values since the true population sizes are unknown. Some of these areas may be surveyed as a more complete test of this technique (or another) in 2005 where known removals will take place.

\section{Forward-Looking Infrared (FLIR)}

The Aerial Research Team contracted Vision Air Research to conduct a two hour test flight using Forward Looking Infrared (FLIR) in a rural area around Boise, ID. The flight was conducted August 21, 2004. We provided parameters to test in regard to altitude, camera angle, and sweeping pattern, and the contractor conducted these procedures while flying over domestic horses and cattle. We used domestic animals in order to evaluate clarity of the video image for a known animal the size and shape of a horse. Utilizing wild horses for this simple test would have required considerably more time and cost without added benefit. The altitudes flown ranged from 1000 to $3000 \mathrm{ft}$ AGL, which was the optimal range suggested by the contractor. Review of the tape raised several concerns regarding resolution/clarity of the image and debate over the species being seen. It was particularly difficult to differentiate between a horse and a cow when the animals were all grazing, but it was relatively easy if the animals had their heads up. Another concern is that in order to capture usable images, the camera must switch to a telephoto mode when animals are spotted. This creates considerable opportunity to miss other animals in the area. In order to get a true representation of the FLIR technology, a survey will be conducted on a known population in 2005.

\section{Discussion and Recommendations}

The aerial surveys conducted thus far could not have been done successfully without the large amount of cooperation and coordination of BLM personnel at the study sites. Piggy-backing flights and sharing costs made these tests much more efficient for everyone and hopefully have expedited the aerial population estimation research effort. We will continue to build this network so that the remaining tests can be equally as efficient for everyone involved.

\section{Proposed Work for 2005}

In addition to the continuance of the field work conducted in 2004, both on the 3 individual-based herds and many population-based herds, the USGS/BRD biologists (F Singer, L Zeigenfuss, J Ransom, K Schoenecker, and J Roelle), in collaboration with BLM specialists and the talented volunteers, will complete a more intense analysis of demographic and genetic data for the Pryor Mountain WHR (years 1992-2004). This information needs to be completely analyzed to compare to herd-level post-treatment effects, including data on: population dynamics and herd growth rates, foaling date patterns, harem dynamics, harem stallion dominance and spatial patterns, mare spatial dynamics by age group, and activity budgets by age group. Pre-treatment data on genetics and heterozygosity must also be analyzed. 
The large increase in predation on this herd dictates that the scientific information be analyzed and reported on now. Also, a new, much smaller, herd carrying capacity has been proposed based on a 2004 comprehensive range health and condition survey (Ricketts, 2004). Questions need to be answered to manage the herd. What is the minimum genetic population size for the herd? Is this compatible with the new range goals? Is the herd genetically healthy and diverse? What are the basic demographic and herd population growth rate parameters? How have these been influenced by predation? What are the outcomes of several potential contraceptive scenarios, combined with the new genetic information? 


\section{Tables and Images}


Table 1. Summary of conditions that existed during behavioral observations for the 2004 field season. (McP $=$ McCullough Peaks WHMA, LBC= Little Book Cliffs WHR, PRY= Pryor Mountain WHR).

$\begin{aligned} & \text { Number of Samples Recorded by Time Period } \\
& \text { 0800-1200 hrs }\end{aligned}$
\begin{tabular}{l|c|c|c|} 
& $\mathbf{1 2 0 0 - 1 6 0 0}$ hrs & \multicolumn{1}{|c|}{$\mathbf{1 6 0 0 - 2 0 0 0 ~ h r s ~}$} \\
McP & 63 & 103 & 51 \\
\cline { 2 - 4 } LBC & 154 & 167 & 135 \\
\cline { 2 - 4 } PRY & 99 & 108 & 99 \\
\cline { 2 - 4 } & &
\end{tabular}

Mean Temperature by Time Period (C)

\begin{tabular}{|c|c|c|c|}
\hline & 0800-1200 hrs & $1200-1600$ hrs & 1600-2000 hrs \\
\hline $\mathrm{McP}$ & 27.56 & 29.79 & 28.24 \\
\hline LBC & 21.01 & 26.30 & 26.24 \\
\hline PRY & 17.26 & 18.08 & 20.39 \\
\hline
\end{tabular}

Mean Climate (occurrence in \% of observations)

\begin{tabular}{|c|c|c|c|}
\hline & Cloud cover & Precipitation & Wind \\
\hline $\mathrm{McP}$ & $35.1 \%$ & $4.4 \%$ & $91 \%$ were $0-10 \mathrm{mph}$ \\
\hline LBC & $52.4 \%$ & $9.8 \%$ & $81 \%$ were $0-5 \mathrm{mph}$ \\
\hline PRY & $49.5 \%$ & $8.5 \%$ & $86 \%$ were $0-10 \mathrm{mph}$ \\
\hline
\end{tabular}

Population

\begin{tabular}{|c|c|c|c|}
\hline & Mean Band Size & Population & Acreage \\
\hline $\mathrm{McP}$ & 8.83 & $493(+/-2)$ & 110,000 \\
\hline LBC & 4.39 & $185(+/-19)$ & 36,113 \\
\hline PRY & 3.38 & $142(+/-12)$ & 39,650 \\
\hline
\end{tabular}


Table 2. Composition of the study herds as calculated on September 30, 2004.

\begin{tabular}{|c|c|c|c|}
\hline & $\begin{array}{c}\text { Pryor Mountain } \\
\text { WHR } \\
\end{array}$ & $\begin{array}{l}\text { McCullough Peaks } \\
\text { WHMA (pre-gather) }\end{array}$ & $\begin{array}{l}\text { Little Book Cliffs } \\
\text { WHR (pre-gather) }\end{array}$ \\
\hline \multirow{3}{*}{$\begin{array}{l}\text { Adult Male } \\
\text { Adult Female } \\
\text { Adult Unknown }\end{array}$} & 63 & 132 & 52 \\
\hline & 58 & 125 & 56 \\
\hline & 0 & 0 & 0 \\
\hline \multirow{3}{*}{$\begin{array}{l}\text { Foal Male } \\
\text { Foal Female } \\
\text { Foal Unknown }\end{array}$} & 2 & 39 & 11 \\
\hline & 2 & 17 & 7 \\
\hline & 0 & 42 & 5 \\
\hline \multirow{3}{*}{$\begin{array}{l}\text { Yearling Male } \\
\text { Yearling Female } \\
\text { Yearling Unknown }\end{array}$} & 2 & 39 & 15 \\
\hline & 5 & 20 & 22 \\
\hline & 0 & 23 & 1 \\
\hline \multirow{3}{*}{$\begin{array}{l}2 \text { yr Male } \\
2 \text { yr Female } \\
2 \text { yr Unknown }\end{array}$} & 6 & 27 & 7 \\
\hline & 4 & 18 & 9 \\
\hline & 0 & 7 & 0 \\
\hline Unknown Horses & 0 & 4 & 0 \\
\hline Missing & 12 & 2 & 19 \\
\hline \multirow{3}{*}{$\begin{array}{l}\text { Adult Mortalities } \\
\text { Yearling Mortalities } \\
\text { Foal Mortalities }\end{array}$} & 1 & 0 & 3 \\
\hline & 15 & 0 & 0 \\
\hline & 24 & 2 & 0 \\
\hline Total Herd & 142 & 493 & 185 \\
\hline
\end{tabular}


Table 3. Post-gather composition of the study herds as calculated on October 15, 2004.

\begin{tabular}{|c|c|c|}
\hline & $\begin{array}{c}\text { McCullough Peaks } \\
\text { WHMA }\end{array}$ & $\begin{array}{c}\text { Little Book Cliffs } \\
\text { WHR } \\
\end{array}$ \\
\hline Adult Male & 57 & 40 \\
\hline Adult Female & 35 & 50 \\
\hline Adult Unknown & 0 & 0 \\
\hline Foal Male & 5 & 1 \\
\hline Foal Female & 2 & 3 \\
\hline Foal Unknown & 0 & 5 \\
\hline Yearling Male & 0 & 4 \\
\hline Yearling Female & 3 & 8 \\
\hline Yearling Unknown & 0 & 0 \\
\hline 2 yr Male & 5 & 2 \\
\hline 2 yr Female & 5 & 7 \\
\hline 2 yr Unknown & 0 & 0 \\
\hline Missing & 0 & 0 \\
\hline Adult Mortalities & 1 & 1 \\
\hline Foal Mortalities & 1 & 0 \\
\hline Removals & 379 & 68 \\
\hline Total Herd & 112 & 120 \\
\hline
\end{tabular}




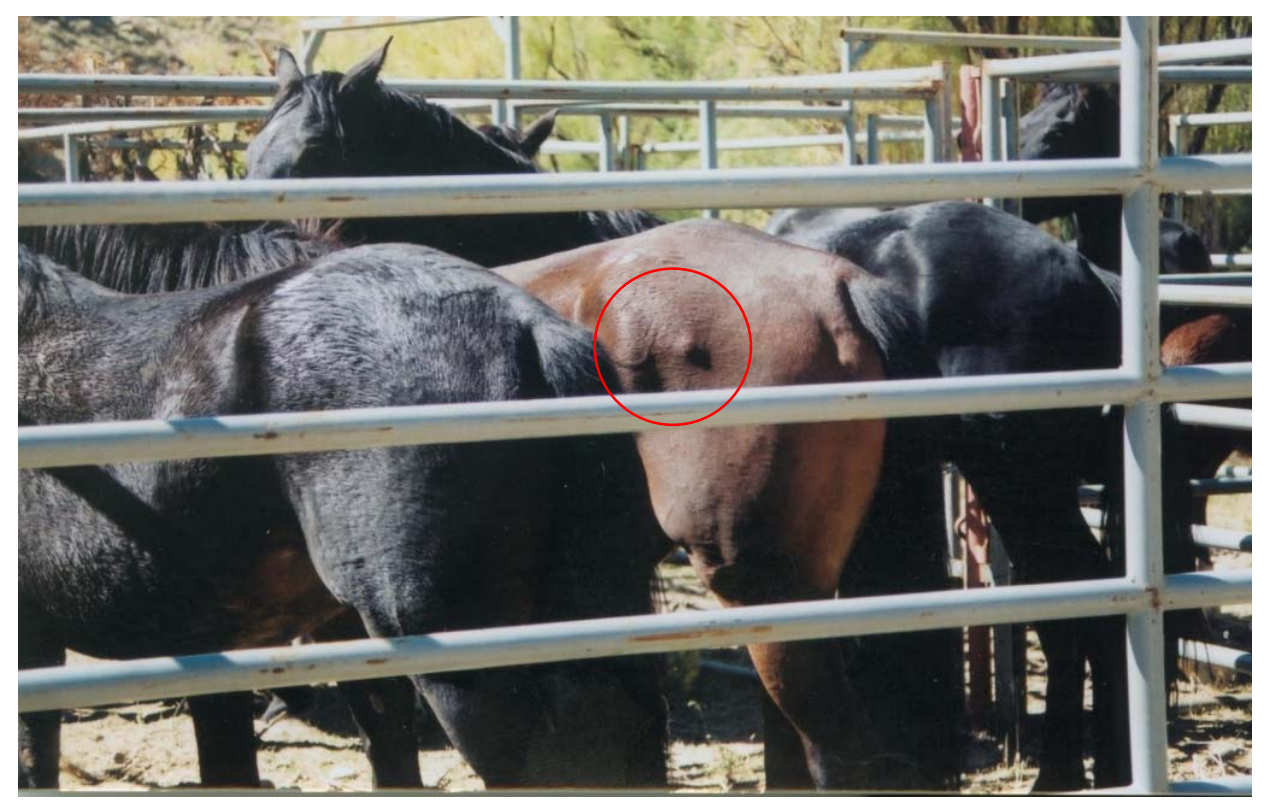

Image 1. Mare \#9910, photographed 10/02/04, swelling from a booster injection on the same day.

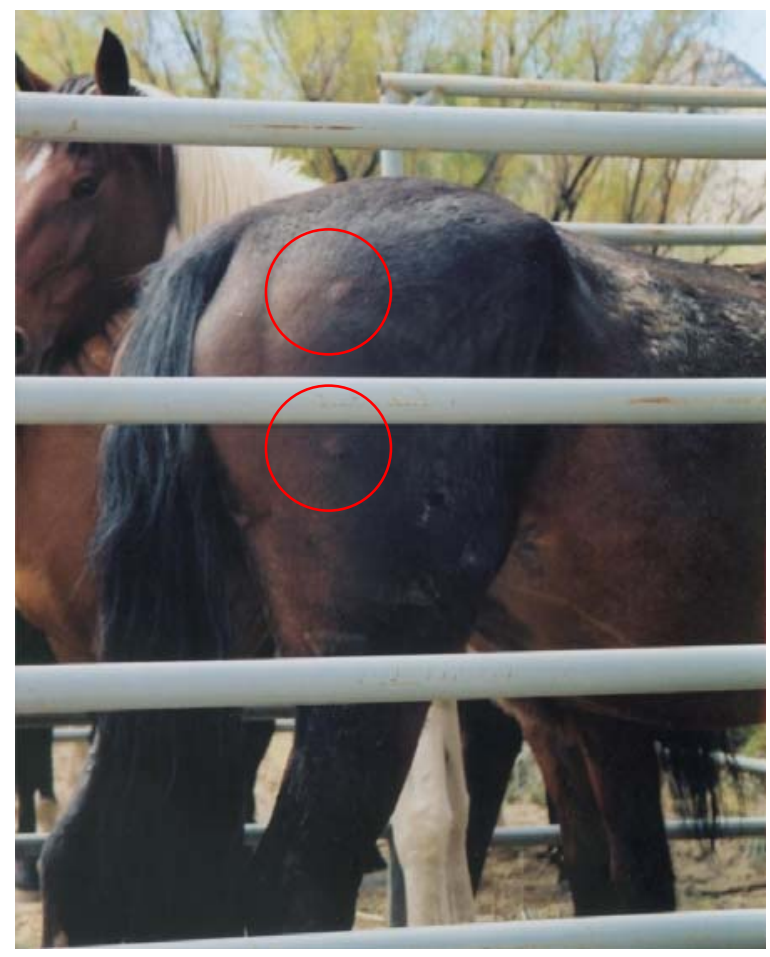

Image 2. Mare \#9604, photographed 10/2/04, persistent nodules from a booster injection on 9/11/03 (upper) and a booster injection on 7/27/04 (lower). 


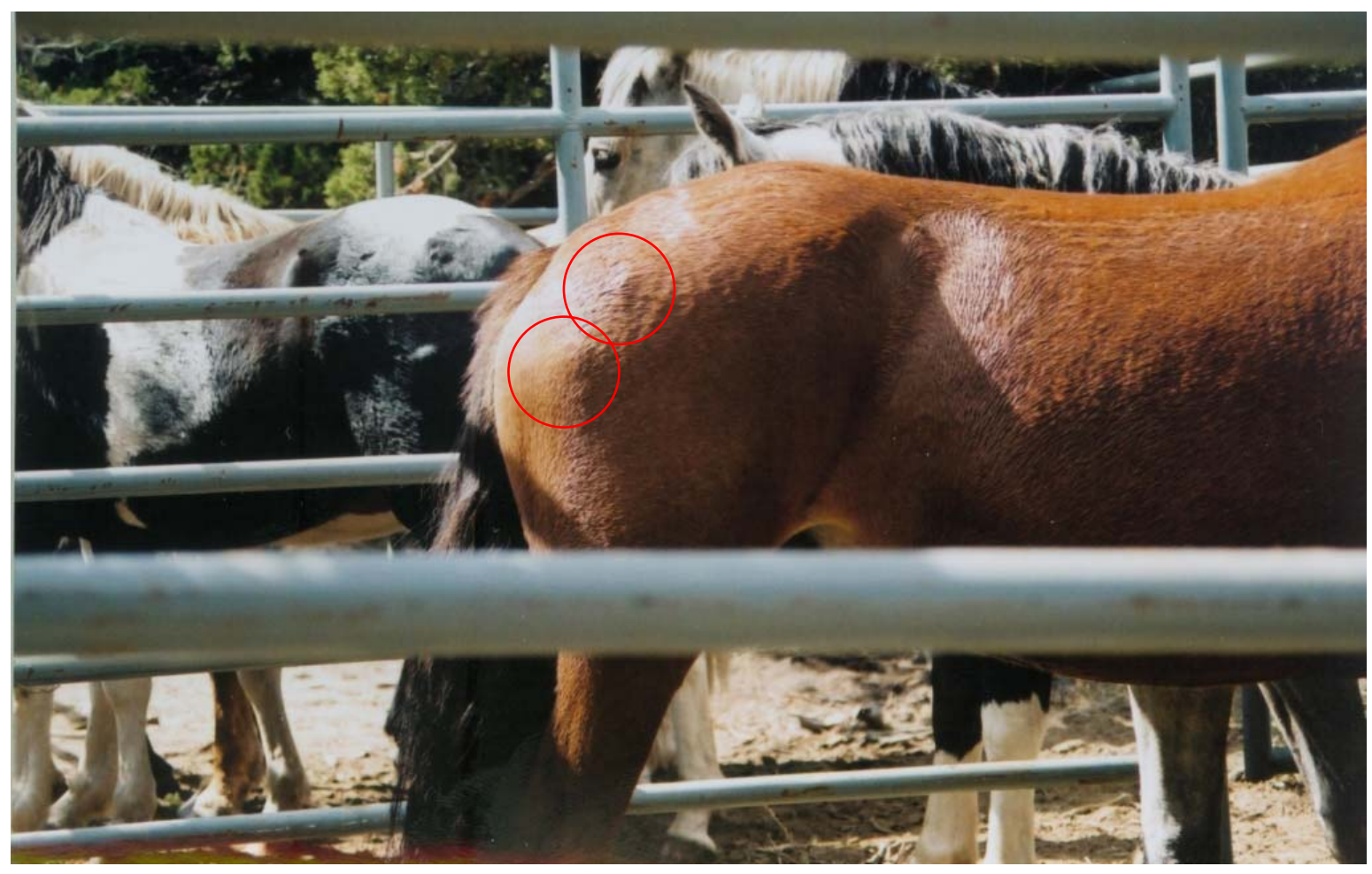

Image 3. Mare \#9030, photographed 10/2/04, persistent nodule from a booster injection on 7/19/04 (upper) and from a booster injection on $4 / 22 / 03$ (lower). 


\section{References}

Fraser, H.M., 1980. Inhibition of reproductive function by antibodies to luteinizing hormone releasing hormone. In J.P. Hearn (Ed.), Immunological aspects of reproduction and fertility control (pp. 143-171), Baltimore: University Park Press.

Liu, I.K.M.,Bernoco, M.,and Feldman, M., 1989. Contraception in mares hereoimmunized with pig zona pellucida. Journal of Reproduction and Fertility, 85, 19-29.

Lubow, Bruce, Ransom, J.I., and Singer, F.J., 2004. Aerial population estimation for wild horses and burros work plan: U.S. Geological Survey, Biological Resources Discipline, and Colorado State University, Fort Collins, Colorado.

Ransom, J.I., Singer, F.J., and Zeigenfuss, L., 2004. Annual report for 2003 wild horse research and field activities: U.S. Geological Survey, Biological Resources Discipline, Open File Report 2004-1264.

Ricketts, M.J., 2004., Pryor Mountain Wild Horse Range Survey and Assessment. Natural Resources Conservation Service, Bozeman, Montana. 148 pp.

Rudman, R., and Keiper, R.R., 1991. The body condition of feral ponies on Assateague island: Equine Veterinary Journal, vol. 12 , no. 6, p. 453-456.

United States Department of the Interior, Bureau of Land Management, 2005. Strategic Research Plan; Wild Horse and Burro Management. Available from the Wild Horse and Burro program website, http://www.wildhorseandburro.blm.gov

United States Department of the Interior, Bureau of Land Management, 2004a. Environmental Assessment Record: WY-020-E04039, McCullough Peaks HMA Gather Plan and Fertility Control Implementation. BLM, Cody Field Office, Wyoming.

United States Department of the Interior, Bureau of Land Management, 2004b. Environmental Assessment Record and Gather Plan: C0-GJF0-04-94-EA, Little Book Cliffs wild horse gather. BLM, Grand Junction Field Office, Colorado.

United States Department of the Interior, Bureau of Land Management, 2004c. Wild Horses: About the Freezemarks. [Data file]. Available from the Wyoming BLM website, http://www.wy.blm.gov/wildhorses/frzmrks.htm

Singer, Francis J., and Coates-Markle, Linda, 2002. Field Trial Plan: Wild Horse Fertility Control - Treatment of wild horse mares with the immunocontraceptive porcine zona pellucida vaccine. U.S. Dept of Interior (BLM, USGS-BRD), Natural Resource Ecology Laboratory of Colorado State University, and Science and Conservation Center of Zoo Montana.

\section{Acknowledgments}

We wish to extend a gracious thank you to the all of the people that generously assisted this project with equipment, office space, housing, vehicles, trail horses, advice, cooperation, aviation, and manpower. Much of this work could not have been completed without the effort and time of many dedicated individuals. Many thanks to the BLM staff of the Wyoming State Office, Nevada State Office, Billings Field Office, Cody Field Office, Lander Field Office, Rock Springs Field Office, Rawlins Field Office, and Winnemucca Field Office for considerable help in coordinating aerial survey research efforts and fertility control endeavors during the gathers. Special thanks to the following:

\section{Animal \& Plant Health Protection Service:}

Albert J. Kane, DVM, MPVM, PhD, Veterinary Epidemiologist and Advisor

\section{Bureau of Land Management:}

Mike Blymyer, Field Manager, Cody Field Office

Dean Bolstad, Lead, Natural Resource Specialist for the Wild Horse and Burro National Program

Jim Dollerschell, Horse Specialist, Little Book Cliffs WHR

Melissa Esser, Field Technician, Pryor Mountain WHR 
Tricia Hatle, Horse Specialist, McCullough Peaks WHMA

Ron Hall, National Wild Horse \& Burro Program, NV office

Heidi Hopkins, Horse Specialist, Winnemucca Field Office

Jane Nibler, Field Technician, Pryor Mountain WHR

Alan Shepherd, WH\&B Lead, WY State Office

\section{Medical College of Ohio:}

John W. Turner, Jr., PhD, Professor of Physiology

\section{National Park Service:}

Darrell Cook, Superintendent, Bighorn Canyon NRA

Bob Byrne, Assistant Superintendent, Bighorn Canyon NRA

Rick Lasko, Integrated Resource Program Manager, Bighorn Canyon NRA

\section{Science and Conservation Center, Zoo Montana:}

Dr. Jay Kirkpatrick, Center Director, consulting fertility control expert

Kim Frank, Conservation Biology Assistant

Robin Lyda, Research Technologist

\section{USGS and CSU:}

Marty Felix, Contractor, Little Book Cliffs WHR

Kayla Grams, Field Technician, Pryor Mountain WHR

Susan Hahn, Field Technician, McCullough Peaks WHMA

Ada Inbody, Volunteer, McCullough Peaks WHMA

Bruce Lubow, PhD, Research Associate, Colorado State University

Georgia Manus, Contractor, Little Book Cliffs WHR

Christina Petrandis, USGS and BLM Technician, Pryor Mountain WHR

Phyllis Preator, Field Technician, McCullough Peaks WHMA

Gerald Thygerson, Field Technician, Little Book Cliffs WHR

\section{University of Kentucky}

E. Gus Cothran, PhD, Director, Equine Parentage Verification and Research Laboratory 


\section{Veterinary Services:}

Lyle Bischoff, DVM, Powell, Wyoming 